\title{
APLIKASI NOTIFIKASI JADWAL KULIAH BAGI MAHASISWA UNIVERSITAS ISLAM LAMONGAN BERBASIS ANDROID
}

\author{
Siti Mujilahwati \\ Dosen Program Studi Teknik Informatika, Fakultas Teknik,Universitas Islam Lamongan \\ Jl. Veteran No. 53 A Lamongan \\ Telp. (0322) 324706 \\ E-mail:moedjee@gmail.com
}

\begin{abstract}
The use of fast and sophisticated technology will make the solution for academics. Lamongan Islamic University (UNISLA) is a private university located in the heart of Lamongan. As a competitive private university, one of them on the use of technology then UNISLA must be able to change and create a manual technology into all-digital technology. One of them is the use of smartphones as a medium of communication and information media. With the support of Informatics engineering program, UNISLA is able to create lecture schedule applications android based. Application that has been made has a feature that the most important is the notification of each user (student). Students will have their respective account as login and setting up the schedule that has been provided by the system according to the student's college schedule, then the system will provide reminder in the form of notification as well as the alarm on each student.
\end{abstract}

Keywords: Apps, Android, Allert, Notification, Schedule

\section{PENDAHULUAN}

Penggunaan smartphone di indonesia menurut survey google belakang ini semakin meningkat, mengingat smartphone sangat penting untuk aktifitas sehari-hari[1] (Auliani, 2015). Dengan hasil riset tersebut maka menjadi incara para pembisnis untuk bersaing dalam inovasi sebuah aplikasi. Semakin banyak pengguna aplikasi tersebut maka inovasi akan semakin digalangkan bagi para developer aplikasi tersebut.

Hampir sama dengan survey google pada penggunaan smartphone yang semakin meningkat, penulis juga mencoba melakukan observasi dan sampling pada seluruh civitas akademik terutama mahasiswa dan juga dosen hampir $90 \%$ mereka telah menggunakan smartphone. Ada sekitar $70 \%$ memakai smartphone berbasi android dan hampir $20 \%$ memakai iPhone. Dari hasil observasi dilapangan Universitas Islam Lamongan (UNISLA) harusnya mampu memanfaatkan teknologi smartphone ini sebagai sarana media informasi baik dibidang akademik maupun yang lainnya. Mengingat jumlah mahasiswa UNISLA yang semakin tahun semakin banyak.

Maka dari hasil sampling tersebut peneliti mencoba memberikan sebuah inovasi untuk informasi jadwal perkuliahan yang dapat diakses dan dipakai melalui smartphone berbasis android. Dengan inovasi aplikasi penjadwalan berbasis android ini nantinya diharapkan akan membantu mahasiswa dan dosen dalam mengingat jadwal masuk kuliah.

Menurut Pratama, (2011) Android adalah sistem operasi untuk telepon seluler berbasis Linux sebagai kernelnya. Saat ini Android bisa disebut raja dari smartphone[2]. Mengapa Android begitu pesat perkembangan di era saat ini? Karena Android menyediakan platform terbuka (Open Source) bagi para pengembang untuk menciptakan aplikasi mereka sendiri. Awalnya, perusahaan search engine terbesar saat ini, yaitu Google Inc. membeli Android Inc. , pendatang baru yang membuat peranti lunak untuk ponsel. Android, Inc. didirikan oleh Andy Rubin, Rich Milner, Nick Sears dan Chris White pada tahun 2003. Pada Agustus 2005 Google membeli Android Inc. Kemudian untuk mengembangkan Android dibentuklah Open Handset Alliance konsorsium dari 34 perusahaan hardware, software dan telekomunikasi, termasuk Google, HTC, Intel, Motorola, Qualqomm, T-Mobile dan Nividia. Saat ini sudah banyak bermunculan vendorvendor untuk smartphone, yaitu diantaranya : HTC, Motorola, Samsung, LG, HKC, Huawei, Archos, Webstation Camangi, Dell, Nexus, SciPhone, WayteQ, Sony Ericsson, Acer, Philips, T-Mobile, Nexian, IMO, Asus dan lainnya vendor yang meproduksi smartphone Android. 
Android menjadi pesaing utama dari produk smartphone lainnya seperti Apple dan BlackBerry. Pesatnya pertumbuhan Android karena Android adalah platform yang sangatlah lengkap baik dari segi sistem operasinya, aplikasi dan tools pengembangannya, market yang menyimpan berbagai aplikasi serta ditambah dengan berbagai dukungan oleh komunitas open source di dunia, sehingga Android berkembang pesat hingga saat ini, baik dari segi teknologi maupun dai segi jumlah device di dunia.

Ada beberapa komponen yang harus dipelajari pada pembuatan aplikasi android diantaranya ada [3] (Mujilahwati, 2016) :

1. Activity

Activity disini adalah sesuatu hal yang berhubungan dengan user interface, pada pemrograman dapat berupa widget. Pada satu aplikasi dapat memiliki beberapa atau lebih dari satu activity, dan setiap satu activity memiliki layer sendiri-sendiri.

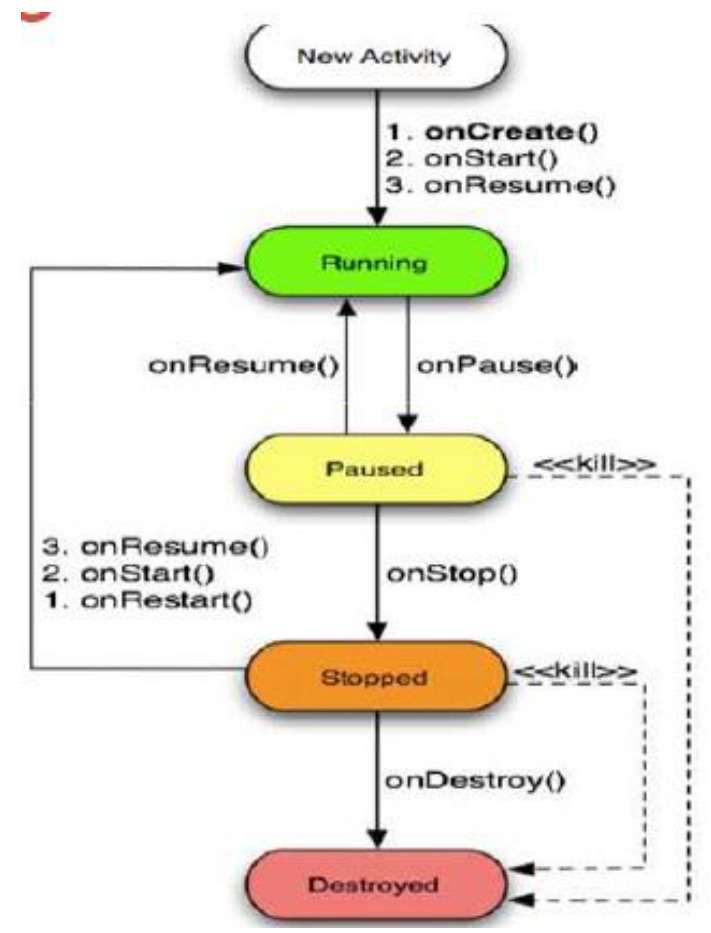

Gambar 1. Masa Hidup Activity Sumber Gambar : Roberto Beraldi

2. Intent

Intent berupa suatu kejadian yang dapat mengantar sebuah pesan antar aplikasi. Bersifat mengirim dan menerima data melalui service.

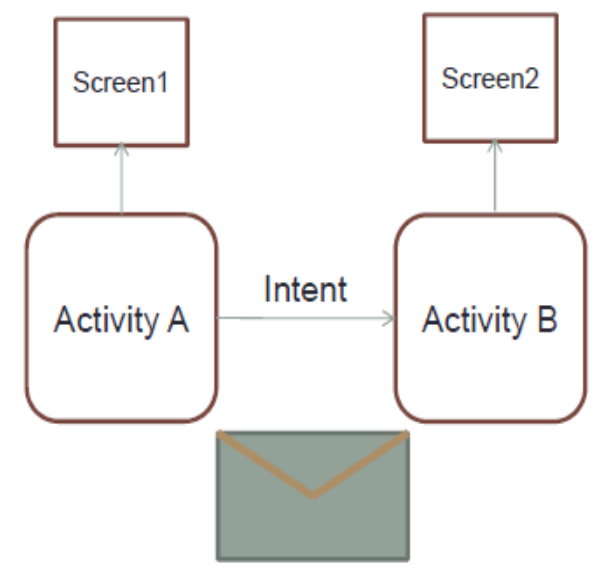

Gambar 2. Penggunaan Intent Sumber Gambar : Roberto Beraldi

\section{Service}

Berbeda dengan activity, service merupakan sebuah kegiatan dibalik layar atau dalam artian tidak tampak secara interface. Dapat diberikan contoh misal pada aplikasi email. Service akan bekerja terus untuk mengecek email yang masuk.

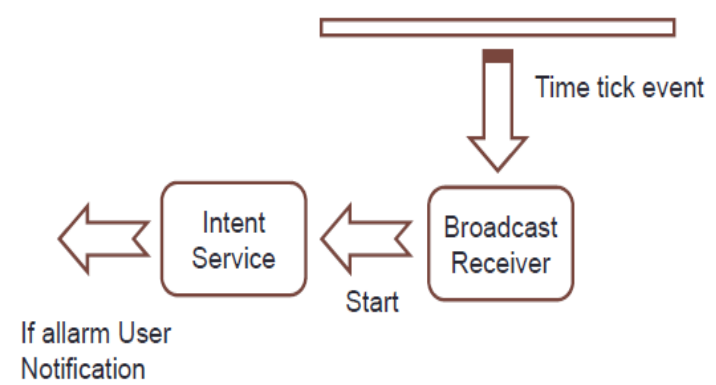

Gambar 3. Service untuk Notifikasi Sumber Gambar : Roberto Beraldi

4. Content Provider

Aplikasi sebagai penyedia content membuat satu set data khusus aplikasi yang tersedia untuk aplikasi lain. Data yang disimpan pada database sqlite.

Sedangkan ada beberapa struktur yang perlu dipahami dalam pembuatan aplikasi android, pembuatan aplikasi android yang dibangun dengan menggunakan android SDK tersusun dari sejumlah direktori dan beberapa file penting yang meruapan satu kesatuan dalam struktur aplikasi android[4]. 
Tabel 1. File pada Struktur Aplikasi Android

\begin{tabular}{|c|c|}
\hline Item & Keterangan \\
\hline /src & $\begin{array}{l}\text { merupakan sebuah } \\
\text { direktori berisi source code } \\
\text { aplikasi, seperti java. }\end{array}$ \\
\hline /res & $\begin{array}{l}\text { Direktori ini berisi semua } \\
\text { resource yang digunakan } \\
\text { aplikasi seperti layout. }\end{array}$ \\
\hline /assets & $\begin{array}{l}\text { Direktori ini berisi file-file } \\
\text { yang dibutuhkan oleh aplikasi } \\
\text { sat run-time. }\end{array}$ \\
\hline /gen & $\begin{array}{l}\text { Direktori ini berisi file-file } \\
\text { yang dihasilkan oleh kompiler } \\
\text { secara otomatis. }\end{array}$ \\
\hline /bin & $\begin{array}{l}\text { Direktori yang berisi file } \\
\text { biner yang dihasilkan oleh } \\
\text { kompiler. }\end{array}$ \\
\hline /libs & $\begin{array}{l}\text { Direktori ini berisi pustaka } \\
\text { yang digunakan aplikasi }\end{array}$ \\
\hline $\begin{array}{l}\text { Android } \\
\text { Manifest.x } \\
\text { ml }\end{array}$ & 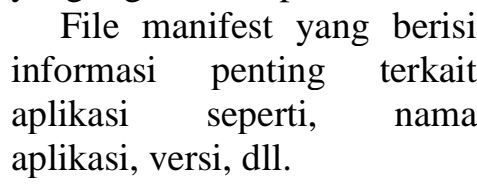 \\
\hline Project. & $\begin{array}{l}\text { File ini berisi daftar target } \\
\text { build. }\end{array}$ \\
\hline
\end{tabular}

Ada beberapa jenis software atau tools untuk develope aplikasi android berdasarkan basic bahasa pemrograman dan teknik penggunaan yang (http://www.jurnalweb.com/tools-untukmembuat-aplikasi-android/, 2016) :

1) Android Studio

2) Androin NDK

3) Unity3D

4) Qt for Android

5) Xamarin

6) Appinventor

7) PhoneGap

8) Android Apps Maker

9) Conduit Mobile

10) iBuildApp

\section{METODELOGI PENELITIAN}

Penelitian ini dilakukan pada UNISLA dengan studi kasus pada mahasiswa fakultas teknik sebagai data data uji aplikasi penjadwalan ini. Jadwal yang dimasukkan pada aplikasi merupakan jadwal dalam satu semester. Adapun metodelogi yang dilakukan dalam penelitian ini adalah :

1) Observasi

Observasi dilakukan pada lingkungan UNISLA yang mencakup pemakaian smartphone pada mahasiswa dan dosen. Observasi ini dilakukan sekitar dua minggu.

2) Kuisioner

Kuisioner ini ditujukan kepada mahasiswa dan dosen, di mana hal-hal yang dimuat pada kuisioner ini mencakup :

a. jenis sistem operasi yang dipakai pada smartphone mahasiswa dan dosen.

b. Pemahaman tentang android.

c. Aplikasi yang sering dipakai.

d. Pemahaman tentang penggunaan aplikasi android.

e. Kebutuhan aplikasi yang di inginkan salah satu fasilitas akademik.

3) Analisis Sistem

Sistem informasi jadwal yang di berikan pada mahasiswa selama iini masih bersifat manual dengan menggunakan format tabel serta dipublikasikan melalui web site, sosial media serta papan media di kampus. Pada sistem seperti ini memiliki beberapa kelemahan walaupun dapat disebar luaskan melalui website dan juga sosial media. Kekurangannya adalah mahasiswa harus menghafal jadwal perkuliahan. Ini akan membuat sulit pada mahasiswa yang mengulang atau mengikuti perkuliahan pada kelas lainnya. Untuk itu diperlukannya inovasi digital yang dapat mempermudah mahasiswa melihat dan mengetahui jadwal kuliah secara real time.

Dari hasil survey menunjukkan bahwa inovasi pada pembuatan informasi jadwal kuliah berupa aplikasi dengan nitifikasi sangat diinginkan oleh mahasiswa dan dosen sehingga selanjutnya dilakukan desain sistem.

4) Desain Sistem

Aplikasi ini didesain dengan sistem bersifat client server, client merupakan mahasiswa dan admin. Admin disini dapat dikerjakan oleh petugas tata usaha. Ada beberapa fitur yang akan diberikan pada masing-masing aktor. Pada dasarnya jadwal akan di inputkan oleh admin sesuai dengan jadwal kelas persemester. Sedangkan mahasiswa hanya bisa memilih jadwal sesuai dengan kelasnya. Untuk lebih detailnya maka desain sistem ini akan di gambarkan seperti pada Gambar 4 berikut ini.

Aplikasi yang akan dibuat memiliki fitur proses yang tergambar pada Gambar 4 memiliki 
dua user, mahasiswa memiliki hak akses login, Lihat dan memilih jadwal kuliah, pengaturan aplikasi, lihat informasi kegiatan, lihat informasi pelanggaran, lihat tugas. Sedangkan admin berhak input jadwal kuliah, input informasi, input pelanggaran dan input tugas.

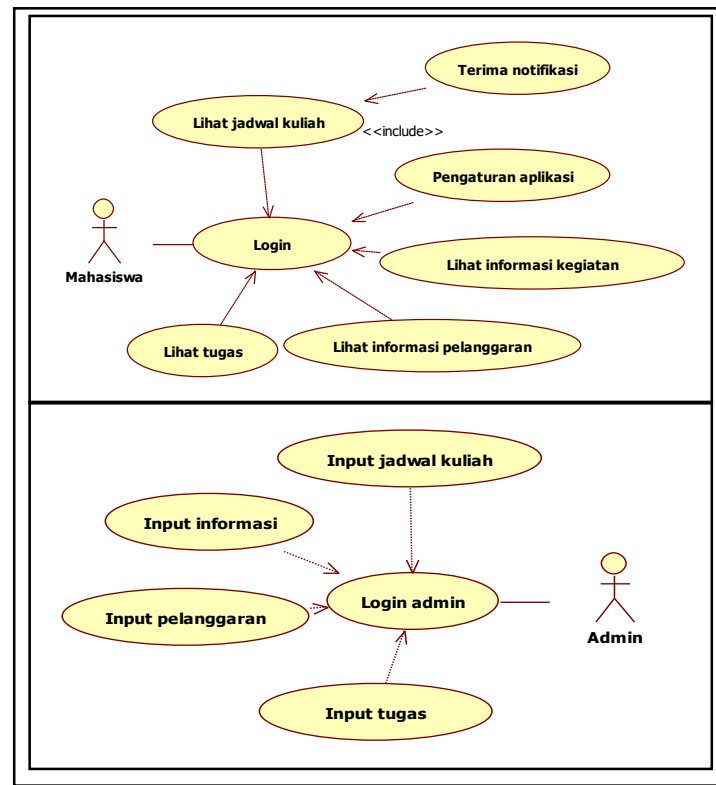

Gambar 4. Use Case Aplikasi Jadwal Kuliah

Beberapa fitur sengaja ditambahkan supaya aplikasi dapat bermanfaat dengan maksimal. Misalkan informasi tugas, apabila dosen memberikan tugas dengan bantuan admin maka tugas dosen tersebut dapat diinformasikan melalui sistem, dan mahasiswa akan menerima notifikasi pada aplikasi yang telah dipasang pada smartphone mereka kalau ada tugas.

5) Implementasi Sistem

Dari perancangan sistem pembuatan aplikasi di atas tampak bahwa usecase mahasiswa dengan usecase admin dipisahkan dengan sebuah kotak, yang memiliki arti bahwa sistem yang dibuat dari dua user ini memiliki basis yang berbeda. Mahasiswa aplikasi yang dibuat dengan basis android, sedangkan admin dibuat aplikasi berbasis web. Sehingga sistem yang dibuat akan bersifat client server. Disinilah service sebuah aplikasi akan bekerja terus menerus mengecek settingan dan juga inputan baru dari server.

Pertama yang harus dilakukan oleh mahasiswa dalam pemakaian aplikasi ini adalah melakukan login dengan akun mereka masingmasing. Username yang digunakan pada proses login ini dengan menggunakan NIM, sedangkan password defaultnya juga NIM akan tetapi mahasiswa dapat merubahnya. Adapun form login yang sudah dibuat seperti pada Gambar 5 berikut ini.

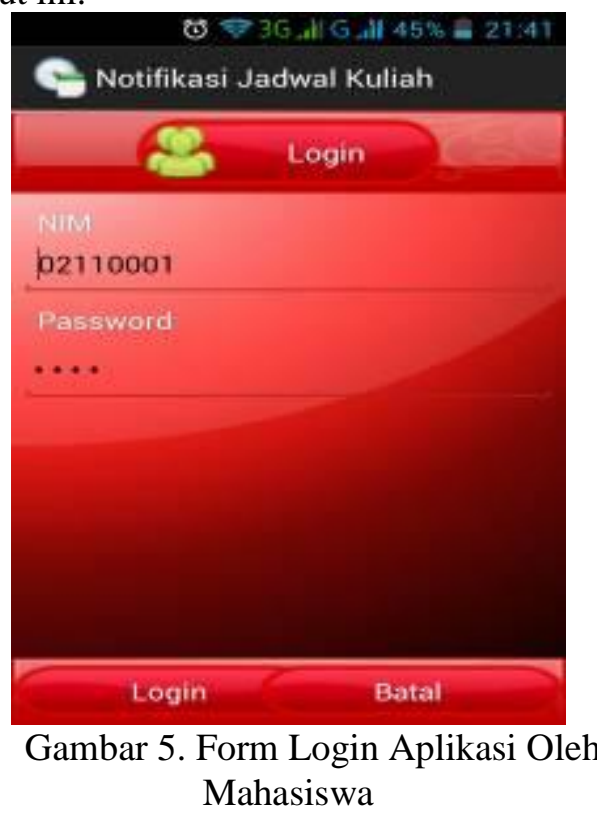

Apabila login sukses maka mahasiswa dapat masuk ke menu utama yang memiliki fitur seperti pada Gambar 6 berikut ini.

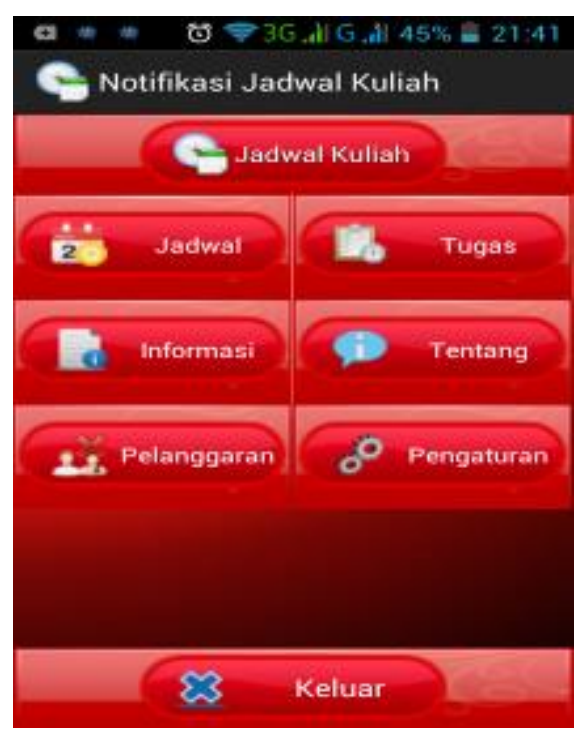

Gambar 6. Form Utama Aplikasi Jadwal

\section{HASIL DAN PEMBAHASAN}

Penelitian ini menghasilkan sebuah aplikasi jadwal kuliah berbasis android, jadwal yang telah dimasukkan pada aplikasi telah disetting berdasarkan semester dan kelas. Pada menu utama jadwal mahasiswa akan emilih smester berapa, dan akan ditampilan jadwal per harinya. Sebagai contoh hasil jadwal kuliah untuk semester 1 hari senin ditunjukkan seperti pada Gambar 7 berikut. 


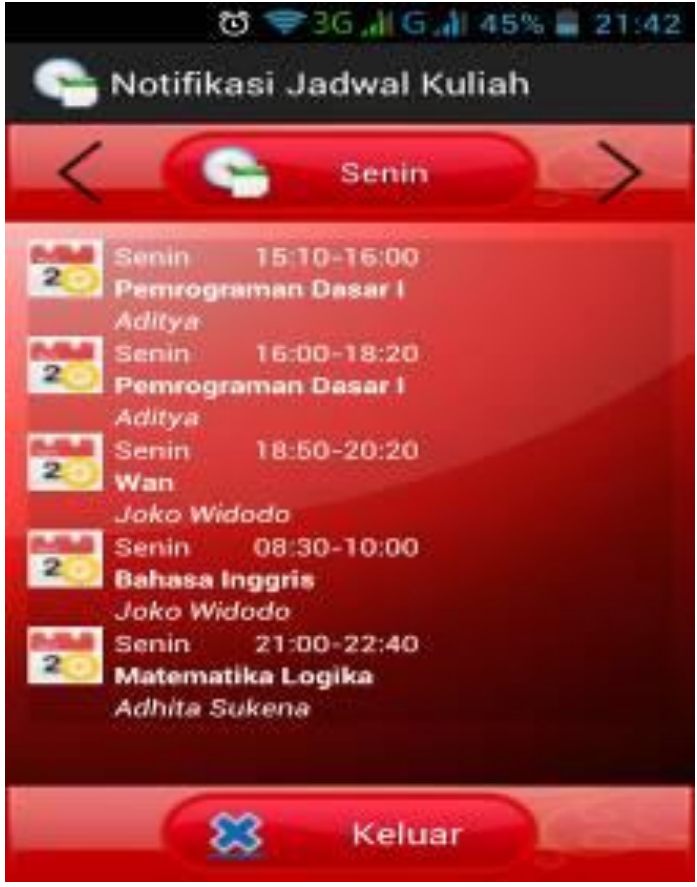

Gambar 7. Tampilan Halaman Jadwal Kuliah

Halaman jadwal kuliah ini digunakan untuk menampilkan jadwal kuliah berdasarkan hari. Yang memuat informasi berupa hari, jam, mata kuliah dan dosennya.

Mahasiswa tidak hanya dapat melihat jadwal melainkan mensetting jadwal kuliah mereka yang berikutnya aplikasi akan mengirimkan notifikasi disetiap jadwal kuliah akan dimulai. Notifikasi ini akan dikirim kepada mahasiswa yang telah menginstal aplikasi yang disesuaikan dengan hari pada smartphone mereka. Notifikasi yang di kirim kepada mahasiswa berdasarkan jadwal harian secara keseluruhan. Hal ini mungkin akan merasa mahasiswa kurang nyaman karena setiap harinya akan menerima notifikasi sebanyak jumlah mata kuliah yang di ikutinya.

Selain itu dengan masuknya banyak notifikasi maka dimungkinkan juga akan memakan memori lebih pada smartphone. Sehingga disarankan kepada mahasiswa setelah mendapatkan notifikasi sesegera mungkin dibuka dan ditutup.

Adapaun hasil notifikasi yang dikirimkan oleh sistem nampak seperti pada Gambar 8 berikut ini.

Tampilan notifikasi masuk ini merupakan daftar notifikasi jadwal yang masuk berdasarkan jadwal mata kuliah yang dipilih oleh mahasiswa. Apabila mahasiswa pada hari senin hanya mengikuti beberapa matakuliah maka mata kuliah yang tidak di ambil tidak perlu diaktifkan. Begitu juga apabila mahasiswa mengikuti mata kuliah pada kelas lain pada hari yang sama maka mahasiswa juga perlu melakukan setting untuk mengaktifkan jadwal mata kuliah dikelas lain pada hari yang sama.

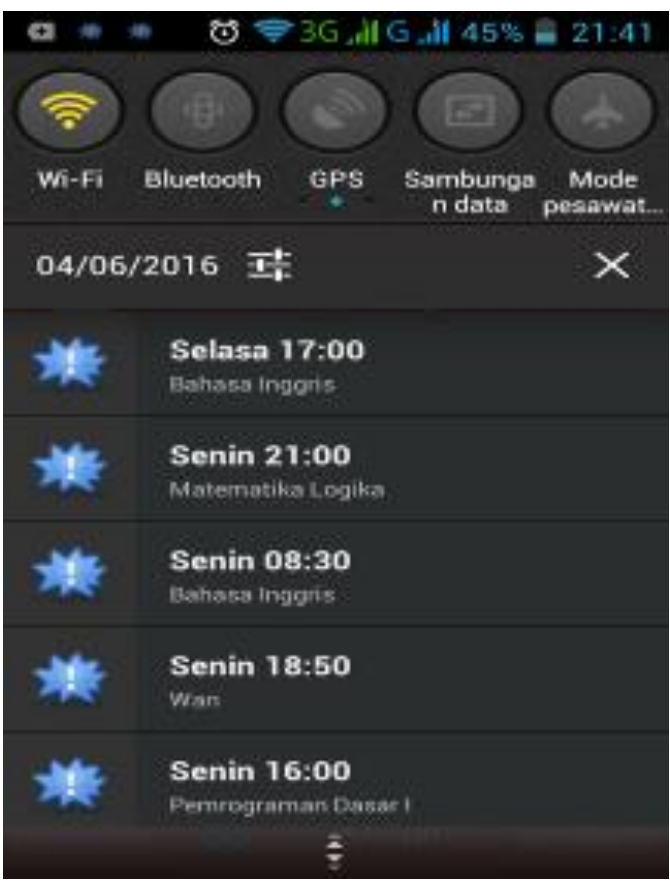

Gambar 8. Tampilan Notifikasi Masuk

\section{KESIMPULAN}

Kesimpulan yang dapat diambil dari penelitian ini adalah sebagai berikut: Kemampuan aplikasi mobile menghadirkan akses data yang cepat dan instan dapat mempermudah mahasiswa untuk mendapatkan jadwal perkuliahan dan informasi terbaru di Universitas Islam Lamongan dengan fitur notifikasinya. Aplikasi android notifikasi ini menggunakan bahasa Java android dan database Mysql sebagai akses sistem client server dalam menghadirkan informasi jadwal seputar perkuliahan. Aplikasi mobile dapat dikembangkan lebih lanjut dengan menambahkan fitur lain seperti push notifikasi untuk menghemat penggunaan memori smartphone mahasiswa. Aplikasi mobile dapat dikembangkan agar tidak hanya untuk Fakultas Teknik saja, tetapi seluruh Fakultas di Universitas Islam Lamongan.

\section{REFERENSI}

[1] Anon., 2016. http://www.jurnalweb.com/tools-untuk- 
membuat-aplikasi-android/. [Online]

[Diakses 10 Maret 2017].

[2] Auliani, P. A., 2015 http://tekno.kompas.com/read/2015/11/19/ 23084827/Mau.Tahu.Hasil.Riset.Google.s oal.Penggunaan.Smartphone.di.Indonesia. [Online] Available at: http://tekno.kompas.com/read/2015/11/19/ 23084827/Mau.Tahu.Hasil.Riset.Google.s oal.Penggunaan.Smartphone.di.Indonesia. [Diakses 1002 2017].

[3] Mujilahwati, S., 2016. Pengembangan Aplikasi Platform Khusus. Lamongan: s.n.

[4] Nugroho. Adi, 2012. Membuat Website Sendiri dengan PHP-MySQL. Mediakita. Yogyakarta.

[5] P.Juhara, Z., 2016. Panduan Lengkap Pemrograman Android. Andi. Yogyakarta.

[6] Pratama, W., 2011. Pengenalan Android. Dalam: TUTORIAL ANDROID PROGRAMMING. s.l.:s.n.

[7] Raharjo Budi, Heryanto Imam, Haryono Arif, 2010. Bahasa Pemrograman. Center Publishing. Yogyakarta. 